\title{
Comparison of Rocuronium and Vecuronium in Patients Undergoing Elective Ultrafast-Track Off-Pump Coronary Artery Bypass Surgery
}

\author{
Kalpana S. Shah ${ }^{1} \quad$ Aayush Kulshrestha ${ }^{1}$ \\ ${ }^{1}$ Department of Anaesthesia, Breach Candy Hospital, Mumbai, \\ Maharashtra, India
}

J Card Crit Care 2020;3:68-76

\begin{abstract}
Address for correspondence Aayush Kulshrestha, DNB, Room no. 22, Godrej Wing, Breach Candy Hospital, 60 A, Bhulabhai Desai Marg, Breach Candy, Cumballa Hill, Mumbai 400026, Maharashtra, India (e-mail: aayush.kul@gmail.com).
\end{abstract}

\begin{abstract}
Keywords

- off-pump coronary artery bypass graft

- rocuronium

- vecuronium

- ultrafast track

Background Neuromuscular blocking drugs are necessary in cardiac surgery to facilitate smooth intubation and ventilation conditions, avoid patient movement, reduce oxygen consumption, and prevent shivering. Hemodynamic stability is very essential in cardiac surgery because the coronary reserve is below normal in such patients.

Aims This study was conducted with the objective of comparing rocuronium, the "near-ideal" muscle relaxant with vecuronium, an already established neuromuscular blocking agent in patients undergoing elective ultrafast-track off-pump coronary artery bypass surgery (CABG).

Settings and Design This prospective, randomized comparative study included 60 patients scheduled for elective off-pump CABG procedures under general anesthesia in the period between May 2015 and March 2016.

Materials and Methods Patients were randomized in equal numbers to either the rocuronium group or the vecuronium group, and intubating conditions and various hemodynamic parameters were observed at different time points.

Statistical Analysis Used Categorical variables were evaluated using the chi-square test, whereas the Student $t$-test or Mann-Whitney test were used for continuous variables.

Results Pulse rate in the rocuronium group was lesser $(79.97 \pm 7.42)(p<0.05)$ at the time of intubation as compared with the vecuronium group $(92.33 \pm 8.93)$. Systolic blood pressure was higher in the vecuronium group $(150.70 \pm 14.05)$ at the time of intubation as compared with the rocuronium group $(130.27 \pm 9.95)(p<0.05)$. Intubating conditions, mean arterial pressure, and diastolic blood pressure changes were similar in both groups.

Conclusions Rocuronium provides good-to-excellent intubating conditions and is devoid of any significant cardiovascular changes causing hemodynamic instability when compared with vecuronium in patients undergoing elective ultrafast-track off-pump CABG.
\end{abstract}

published online April 15, 2020
DOI https://doi.org/

10.1055/s-0040-1709966 ISSN 2457-0206.
C2020 Official Publication of The Simulation Society (TSS), accredited by International Society of Cardiovascular Ultrasound (ISCU).
License terms

(ㅇ) (1) $\ominus \circledast$ 


\section{Introduction}

Coronary artery bypass grafting (CABG) is one of the most commonly performed surgical procedures worldwide. Laryngoscopy and endotracheal intubation, an integral part of general anesthesia for cardiac surgery, is a noxious stimulus in itself and can provoke untoward sympathetic responses in the cardiovascular, respiratory, and other physiological systems of the body. ${ }^{1}$ Such hemodynamic changes that occur during intubation may alter the delicate and critical balance between myocardial oxygen demand and supply and thus may precipitate myocardial ischemia in patients with coronary artery disease.

Ultrafast tracking anesthesia refers to extubation within 2 hours of the end of surgery and is now an accepted technique in cardiac surgery.

Neuromuscular blocking drugs are necessary in cardiac surgery to facilitate smooth intubation and ventilation conditions, avoid patient movement, decrease oxygen consumption, and avoid shivering. ${ }^{2}$ Hemodynamic stability is very essential in cardiac surgery because the coronary reserve is below normal in such patients. Any factor that augments the myocardial oxygen demand by increasing the heart rate (HR), myocardial contractility, or the systemic vascular resistance, or by changing the blood pressure (BP) is considered to be detrimental. It is therefore necessary to avoid any agent that stimulates the cardiovascular system and increases the myocardial oxygen demand. Thus, in selecting a neuromuscular blocking agent, an anesthesiologist strives to achieve three competing goals: smooth intubating conditions, hemodynamic stability, and rapid predictable recovery from the muscle relaxant.

Intravenous vecuronium bromide, an intermediateacting nondepolarizing muscle relaxant, is widely used and is considered the "gold standard" among muscle relaxants for its cardiovascular stability. ${ }^{3,4}$ On the other hand, intravenous rocuronium bromide is a relatively new steroidal intermediate-acting nondepolarizing neuromuscular blocking agent with a faster onset of action. ${ }^{5}$

The aims of this study are to compare rocuronium, the "near-ideal" muscle relaxant, with vecuronium, an already established neuromuscular blocking agent in patients undergoing elective ultrafast-track off-pump CABG surgery.

\section{Subjects and Methods}

This prospective, randomized comparative study included 60 patients scheduled for elective ultrafast-track off-pump CABG procedures under general anesthesia in the period between May 2015 and March 2016. The study was commenced after taking permission from the Ethics Committee. Patients aged between 30 and 65 years of both genders and belonging to class 3 or 4 of the American Society of Anesthesiologists (ASA) grading were included in the study. Patients with valvular pathologies or prosthetic valves, with ejection fraction less than $25 \%$, with allergies to any of the two drugs used, with difficult intubation (Mallampati grade 3 and 4), suffering from neuromuscular, hepatic, or renal disorders, or those who refused to be a part of the study were excluded.

Each patient was screened a day before the surgery, and a complete history, general, and systemic examination was performed. All baseline investigations including a complete blood count, renal function test, liver function test, cholesterol studies, testing for hepatitis B and HIV (human immunodeficiency virus), chest X-ray, electrocardiography, echocardiography, angiography, pulmonary function test, and carotid Doppler studies were performed and reviewed. To ascertain the ease of intubation, every patient was examined for grading as per the Mallampati classification. A thorough preanesthetic counseling was provided, and informed written consent was obtained from them.

A total of 60 patients were randomly allocated into two different groups of 30 patients each using simple randomization methods. Patients in group $\mathrm{R}$ received rocuronium $(0.6 \mathrm{mg} / \mathrm{kg})$, whereas patients in group $\mathrm{V}$ received vecuronium $(0.1 \mathrm{mg} / \mathrm{kg})$. For this study, sample size, was determined based on the standard deviations in HR in previous similar reference studies. ${ }^{6}$

A specially designed data collection sheet was used to record the particulars of the patients, the anesthetic details, the grades of relaxation, and intraoperative monitoring parameters. The parameters studied included the following: HR, systolic BP (SBP), diastolic BP (DBP), and mean arterial pressure (MAP). These were measured at the following steps; baseline, preinduction, induction, postinduction, at intubation, postintubation, and then at 1, 3, 5, 10, and 15 minutes.

\section{Anesthetic Procedure}

On arrival in the operating room, the patient's basal parameters were recorded through pulse oximetry, noninvasive BP monitoring, and electrocardiography. Intravenous (IV) access using 16-gauge cannula was established, and an IV infusion of Ringer's lactate was started. Midazolam $0.02 \mathrm{mg} / \mathrm{kg}$ was given. An invasive BP monitoring line was placed (radial artery $20 \mathrm{G}$ ) under local anesthesia. Right internal jugular venous cannulation was performed under local anesthesia for central venous pressure monitoring. All patients were premedicated with fentanyl $1 \mu \mathrm{g} / \mathrm{kg}$, ondansetron $0.08 \mathrm{mg} / \mathrm{kg}$, and glycopyrrolate $0.01 \mathrm{mg} / \mathrm{kg}$ intravenously. After preoxygenating the patient with $100 \%$ oxygen, anesthesia induction was performed with propofol $2 \mathrm{mg} / \mathrm{kg}$.

After induction, patients belonging to group $\mathrm{R}$ or group $\mathrm{V}$ received either the intubating dose of rocuronium $(0.6 \mathrm{mg} / \mathrm{kg}$ body weight) or vecuronium ( $0.1 \mathrm{mg} / \mathrm{kg}$ body weight) intravenously, respectively. Patients who received rocuronium bromide were mask ventilated with $50 \%$ nitrous oxide, $50 \%$ oxygen, and $1 \%$ sevoflurane for 90 seconds, whereas those who received vecuronium bromide were mask ventilated with $50 \%$ nitrous oxide, $50 \%$ oxygen, and sevoflurane $1 \%$ for 3 minutes. In patients who received the intubating dose of rocuronium bromide, laryngoscopy was performed at the end of 90 seconds; in those who received vecuronium bromide, laryngoscopy was performed at the end of 180 seconds. 
Intubating conditions in both groups were evaluated and graded according to the four-step scale proposed by Goldberg et al as follows ${ }^{7}$ :

- Grade 1 (excellent): good jaw relaxation, vocal cords relaxed, and easy passage of the endotracheal tube without coughing.

- Grade 2 (good): jaw well relaxed, vocal cords relaxed, and passage of the tube with slight cough.

- Grade 3 (poor): passage of the tube with moderate coughing or bucking, some vocal cord movements.

- Grade 4 (impossible): jaw not relaxed, vocal cords adducted or not visualized, and passage of the tube impossible.

Hemodynamic parameters including the HR, SBP, DBP, and MAP were measured at baseline, preinduction, induction, postinduction, at intubation, and then at $1,3,5,10$, and 15 minutes.

Anesthesia was maintained with a combination of $50 \%$ oxygen, $50 \%$ nitrous oxide, and sevoflurane through a closed circuit on volume-controlled ventilation with a tidal volume of 8 to $10 \mathrm{~mL} / \mathrm{kg}$ and a respiratory rate adjusted to keep the end-tidal carbon dioxide concentration at 30 to $35 \mathrm{~mm}$ of $\mathrm{Hg}$. Muscle relaxation was achieved with an intermittent dose of rocuronium or vecuronium depending on the studied group.

At the end of surgery, when the patient attempted to breathe, residual neuromuscular blockade was reversed with neostigmine $0.05 \mathrm{mg} / \mathrm{kg}$ and glycopyrrolate $0.01 \mathrm{mg} / \mathrm{kg}$. After confirming hemodynamic stability, normothermia, adequate blood gas exchange, adequate muscle strength, satisfactory urine output, acceptable hematocrit, chest tube drainage, and adequate pain control, the patient was extubated on the table in the operating room after thorough oral suctioning. Postextubation, patients were shifted to the postanesthesia care unit.

\section{Statistical Analysis}

Data entry was performed using Microsoft Excel, and data analysis was performed using the Statistical Package for Social Sciences (SPSS), Version 15 (SPSS Inc.) and SigmaPlot, Version 12 (Systat Software Inc.). Quantitative data are presented with the help of mean, standard deviation, median, and interquartile range. Based on data characteristics and the standard error of difference between two means, the Student $t$-test or Mann-Whitney test was used for the analysis of primary and secondary variables. The association among study groups was assessed using the chi-square test. A p-value of less than 0.05 was considered to be significant.

\section{Results}

A total of 60 patients were randomly allocated into two different groups of 30 patients each. The demographic profile of patients in both groups is shown in - Table 1 .

The mean age was $56.53 \pm 5.98$ in group $R$ and $58.27 \pm 7.05$ in group $V$, with no statistically significant difference between both groups $(p=0.308$. There was a male preponderance in both groups, with no statistical difference $(p=0.781)$.
Table 1 Demographic profile of patients in the group receiving rocuronium (group $R$ ) and vecuronium (group $V$ )

\begin{tabular}{|l|l|l|}
\hline Variable & Group R & Group V \\
\hline No. of patients & 30 & 30 \\
\hline Age & $56.53 \pm 5.98$ & $58.27 \pm 7.05$ \\
\hline Sex & 21 & 20 \\
\hline Male & 9 & 10 \\
\hline Female & 26 & 27 \\
\hline ASA & 4 & 3 \\
\hline Grade 3 & $76.53 \pm 8.80$ & $73.17 \pm 8.66$ \\
\hline Grade 4 &
\end{tabular}

Abbreviation: ASA, American Society of Anesthesiologists.

Table 2 Comparison of grades of relaxation among the study groups

\begin{tabular}{|l|l|l|}
\hline Grade of relaxation & \multicolumn{2}{|c|}{ Study groups } \\
\cline { 2 - 3 } & Group R & Group V \\
\hline 1 & 29 & 26 \\
\hline 2 & 1 & 4 \\
\hline
\end{tabular}

In group R, 26 patients were ASA grade 3 and only 4 patients were ASA grade 4. Similarly, in group V, 27 patients were ASA grade 3 and only 3 patients were ASA grade 4 . No statistical difference was noted between the groups ( $p=0.343$ ).

There was no statistically significant difference between both groups regarding weight $(76.53 \pm 8.80 \mathrm{~kg}$ in group $\mathrm{R}$ and $73.17 \pm 8.66 \mathrm{~kg}$ in group $\mathrm{V} ; p=0.141)$.

Comparing the grades of relaxation in both the study groups, $86.70 \%$ patients in group $\mathrm{V}$ had grade 1 relaxation and $13.3 \%$ had grade 2 relaxation, whereas in group R, $96.70 \%$ patients had grade 1 and $3.30 \%$ had grade 2 relaxation. None of the patients had grade 3 or 4 relaxation in both groups ( - Table 2). There was no statistical difference seen between the two groups.

Basal HR was $85.90 \pm 10.64$ in group V $81.33 \pm 9.58$ in group $\mathrm{R}$, which were comparable to each other $(p>0.001)$. During preinduction, a fall in HR was observed in both groups; however, the fall was not clinically significant. At induction, the HR was $82.90 \pm 10.17$ in group $V$ and $78.60 \pm 6.86$ in group $R$. Postinduction, a slight fall in HR was observed in group V, with an HR of $81.23 \pm 10.08$, compared with group $R$, where a slight rise in HR was observed, with an HR of $79.73 \pm 7$.43. Both induction and postinduction changes in HR were not statistically significant between the two groups. A significant rise in HR was observed in group $\mathrm{V}$ during intubation (T0), with HR increased to $92.33 \pm 8.93$, compared with group $R$, where a minimal rise in HR was observed, with an HR of $79.97 \pm 7.42$. Postintubation, the HR remained between $88.00 \pm 8.72$ and $80.30 \pm 7.59$ in group $V$ and between $73.07 \pm 7.55$ and $69.83 \pm 5.21$ in group $R$. During intubation and postintubation, a significant rise in HR was observed in group $\mathrm{V}$, whereas the HR remained stable in

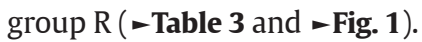


Table 3 Comparing the HR in both groups

\begin{tabular}{|l|l|l|l|l|l|l|l|}
\hline HR (per min) & \multicolumn{3}{|c|}{ Group V $(N=30)$} & \multicolumn{3}{c|}{ Group R $(N=30)$} & Malue \\
\hline Time & Mean & $\begin{array}{l}\text { Standard } \\
\text { deviation }\end{array}$ & Median & Mean & $\begin{array}{l}\text { Standard } \\
\text { deviation }\end{array}$ & Median \\
\hline Basal & 85.90 & 10.64 & 86.00 & 81.33 & 9.58 & 78.00 & 0.086 \\
\hline Preinduction & 83.13 & 9.94 & 84.50 & 79.13 & 8.62 & 78.00 & 0.101 \\
\hline Induction & 82.90 & 10.17 & 83.00 & 78.60 & 6.86 & 75.50 & 0.060 \\
\hline Postinduction & 81.23 & 10.08 & 81.00 & 79.73 & 7.43 & 78.00 & 0.131 \\
\hline T0 & 92.33 & 8.93 & 91.00 & 79.97 & 7.42 & 78.00 & $<0.001$ \\
\hline T1 & 88.00 & 8.72 & 89.00 & 73.07 & 7.55 & 72.00 & $<0.001$ \\
\hline T3 & 85.00 & 7.88 & 87.50 & 71.60 & 5.83 & 71.00 & $<0.001$ \\
\hline T5 & 82.20 & 9.55 & 83.00 & 70.97 & 5.88 & 70.00 & $<0.001$ \\
\hline T10 & 81.37 & 7.65 & 82.00 & 69.70 & 5.09 & 69.50 & $<0.001$ \\
\hline T15 & 80.30 & 7.59 & 81.00 & 69.63 & 5.21 & 69.00 & $<0.001$ \\
\hline
\end{tabular}

Abbreviation: HR, heart rate.

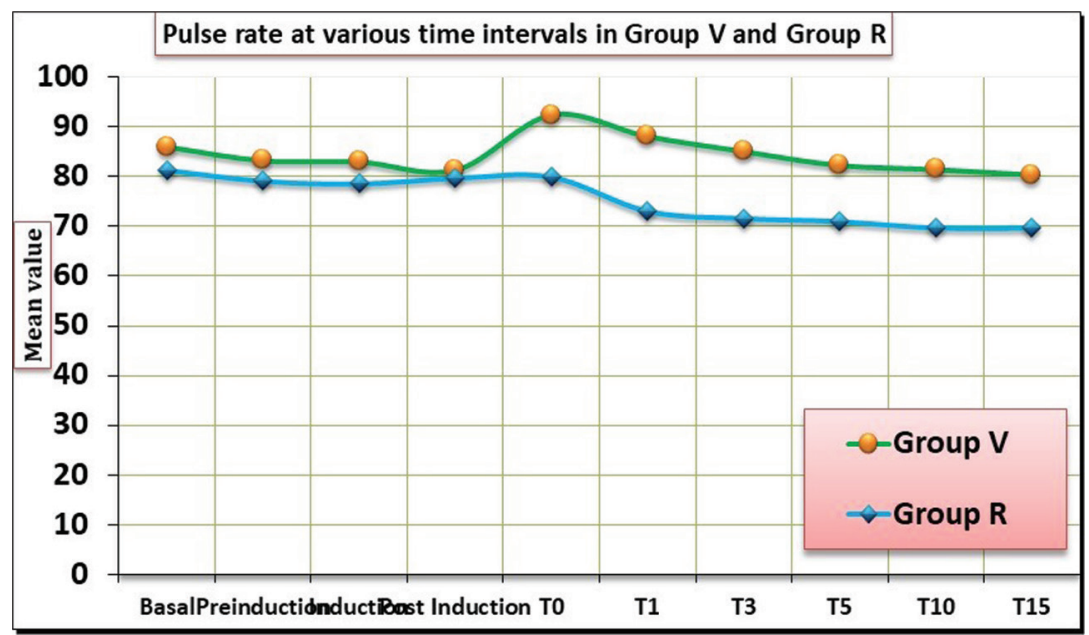

Fig. 1 Pulse rate at various time intervals in group $V$ and group $R$.

Basal mean SBP was comparable in both groups ( $p>0.001$ ). After premedication, a comparable fall in SBP was observed in both groups. At induction, the difference in SBP was statistically significant among the groups. Postinduction, a slight increase in SBP was noted in both groups. In group V, SBP increased from $140.30 \pm 16.31$ to $142.83 \pm 13.90$, whereas in group $R$, it increased from $128.47 \pm 12.03$ to $130.23 \pm 11.23$. This change was statistically significant. At intubation (T0) and postintubation for 15 minutes, there was a significant rise in SBP in group $V$ compared with group $R(p<0.001)$. In group V, it was observed at T3 that SBP dropped to basal SBP and remained between $142.60 \pm 15.13$ and $134.70 \pm 14.94$. Group R postintubation SBP remains between $125.03 \pm 8.09$ to $118.73 \pm 6.15$ ( $\boldsymbol{- \text { Table }} 4$ and $\boldsymbol{~ - ~ F i g . ~} 2$ ).

Basal DBP in both groups was comparable $(p>0.05)$. With premedication in the preinduction period, a fall in DBP was observed in both groups. At induction, DBP was comparable. Postinduction, a slight increase in DBP was observed in both groups. In group V, DBP increased from $75.33 \pm 9.74$ to $77.73 \pm 9.98$, whereas in group $\mathrm{R}$, DBP increased from
$71.10 \pm 6.73$ to $72.00 \pm 6.98$. However, there was no significant association $(p>0.05)$ found between the two groups. At intubation (T0), a slight increase in DBP was noted in both groups. DBP remained between $76.80 \pm 8.00$ and $72.40 \pm 5.99$ in group $\mathrm{V}$ and between $69.70 \pm 6.73$ and $67.33 \pm 6.76$ in group R. At no point during the study was there a significant difference in DBP in group $V$ and $R(-$ Table 5 and $\boldsymbol{- F i g}$. 3 ).

Basal MAP was comparable in both groups $(p>0.05)$. A fall in MAP was observed in both groups during preinduction, with an MAP of $96.37 \pm 11.70$ from a basal value of $99.97 \pm 10.50$ in group $V$ and $93.90 \pm 7.22$ from a basal value of $97.27 \pm 9.01$ in group R. At induction, the MAP was comparable among the groups. Postinduction, a slight increase in MAP was observed in both groups, with an MAP of $99.17 \pm 10.22$ in group $V$ and $91.43 \pm 6.70$ in group R; however, the difference was not significant ( $p>0.05$ ). During intubation (T0), a rise in MAP was observed in group V, with an MAP of $102.10 \pm 8.55$ compared with $91.63 \pm 7.18$ in group R. However, the difference was not significant $(p>0.05)$. Postintubation (T1-T15), MAP was between $97.83 \pm 20.10$ and $94.00 \pm 8.17$ in group $V$ and 
72 Shah, Kulshrestha

Table 4 Comparing the SBP in both groups

\begin{tabular}{|l|l|l|l|l|l|}
\hline \multirow{2}{*}{ SBP $(\mathrm{mm} \mathrm{Hg})$} & \multicolumn{2}{|c|}{ Group V $(N=30)$} & \multicolumn{2}{c|}{ Group R $(N=30)$} & $p$-Value \\
\cline { 2 - 6 } & Mean & $\begin{array}{l}\text { Standard } \\
\text { deviation }\end{array}$ & Mean & $\begin{array}{l}\text { Standard } \\
\text { deviation }\end{array}$ \\
\hline Basal & 144.63 & 16.42 & 140.57 & 16.32 & 0.340 \\
\hline Preinduction & 140.40 & 16.64 & 136.17 & 15.64 & 0.314 \\
\hline Induction & 140.30 & 16.31 & 128.47 & 12.03 & 0.002 \\
\hline Postinduction & 142.83 & 13.90 & 130.23 & 11.23 & 0.002 \\
\hline T0 & 150.70 & 14.05 & 130.27 & 9.95 & $<0.001$ \\
\hline T1 & 147.60 & 13.24 & 125.03 & 8.09 & $<0.001$ \\
\hline T3 & 142.60 & 15.13 & 122.50 & 7.62 & $<0.001$ \\
\hline T5 & 137.97 & 14.71 & 120.10 & 6.29 & $<0.001$ \\
\hline T10 & 136.53 & 15.07 & 118.10 & 6.69 & $<0.001$ \\
\hline T15 & 134.70 & 14.94 & 6.15 & $<0.001$ \\
\hline
\end{tabular}

Abbreviation: SBP, systolic blood pressure.

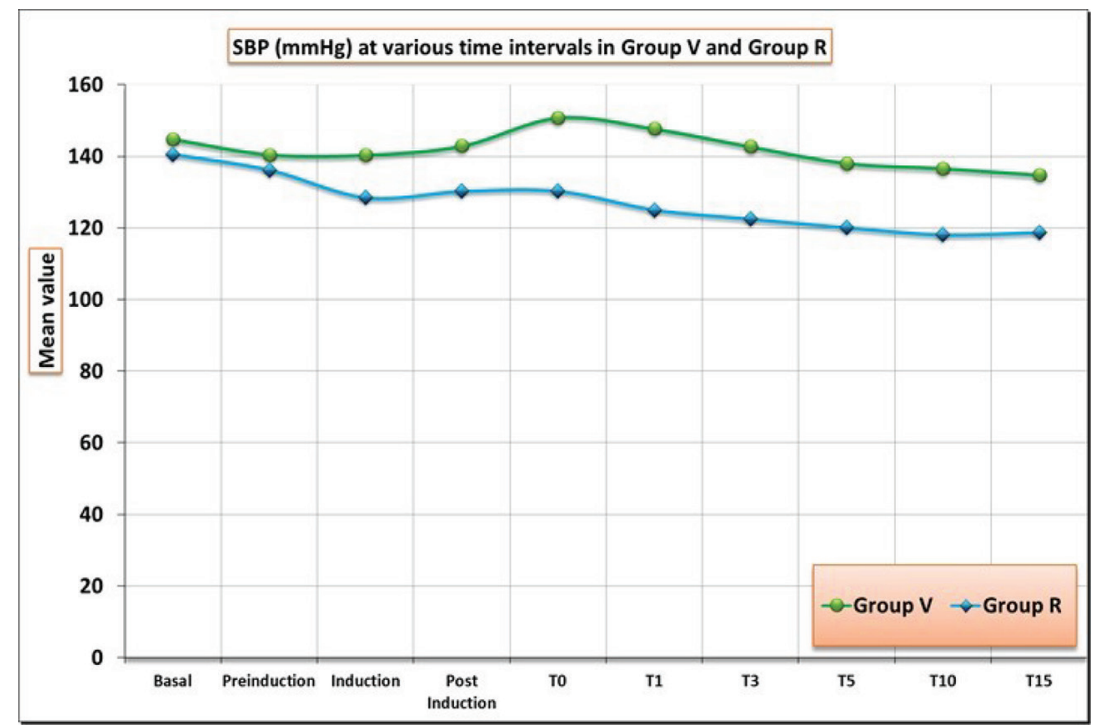

Fig. 2 SBP at various time intervals in group $V$ and group R. SBP, systolic blood pressure.

Table 5 Comparing the DBP in both groups

\begin{tabular}{|c|c|c|c|c|c|}
\hline \multirow[t]{2}{*}{ DBP (mm Hg) } & \multicolumn{2}{|c|}{ Group V $(N=30)$} & \multicolumn{2}{|c|}{ Group $\mathrm{R}(N=30)$} & \multirow[t]{2}{*}{$p$-Value } \\
\hline & Mean & $\begin{array}{l}\text { Standard } \\
\text { deviation }\end{array}$ & Mean & $\begin{array}{l}\text { Standard } \\
\text { deviation }\end{array}$ & \\
\hline Basal & 81.13 & 10.23 & 77.40 & 7.22 & 0.108 \\
\hline Preinduction & 76.83 & 9.30 & 74.30 & 6.97 & 0.237 \\
\hline Induction & 75.33 & 9.74 & 71.10 & 6.73 & 0.055 \\
\hline Postinduction & 77.73 & 9.98 & 72.00 & 6.98 & 0.056 \\
\hline T0 & 78.33 & 9.09 & 73.20 & 7.27 & 0.058 \\
\hline T1 & 76.80 & 8.00 & 69.70 & 6.73 & 0.102 \\
\hline T3 & 76.20 & 7.58 & 69.57 & 6.34 & 0.103 \\
\hline T5 & 72.43 & 5.94 & 68.20 & 4.94 & 0.087 \\
\hline $\mathrm{T} 10$ & 73.33 & 5.54 & 67.90 & 5.67 & 0.092 \\
\hline DBP T15 & 72.40 & 5.99 & 67.33 & 6.76 & 0.085 \\
\hline
\end{tabular}

Abbreviation: DBP, diastolic blood pressure. 


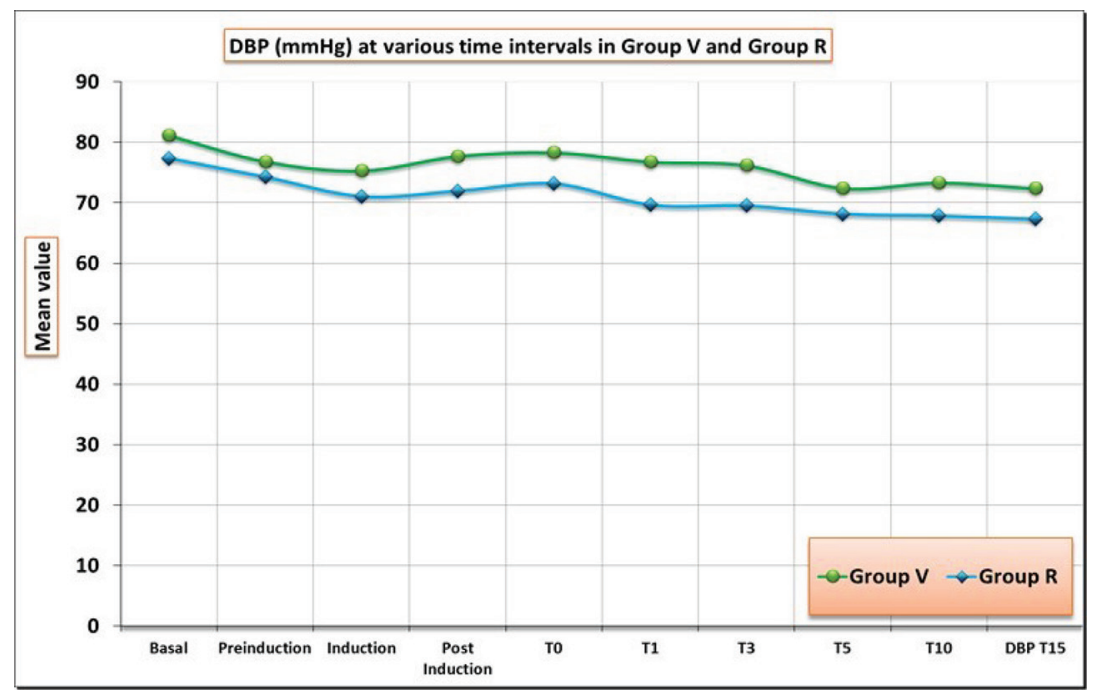

Fig. 3 DBP at various time intervals in group $V$ and group R. DBP, diastolic blood pressure.

Table 6 Comparing the MAP in both groups

\begin{tabular}{|l|l|l|l|l|l|}
\hline \multirow{2}{*}{ MAP (mm Hg) } & \multicolumn{2}{|c|}{ Group V $(N=30)$} & \multicolumn{3}{c|}{ Group $\mathrm{R}(N=30)$} \\
\cline { 2 - 6 } & Mean & Standard deviation & Mean & Standard deviation \\
\hline Basal & 99.97 & 10.50 & 97.27 & 9.01 & 0.290 \\
\hline Premedication & 96.37 & 11.70 & 93.90 & 7.22 & 0.330 \\
\hline Induction & 96.97 & 11.04 & 89.37 & 6.82 & 0.103 \\
\hline Postinduction & 99.17 & 10.22 & 91.43 & 6.70 & 0.059 \\
\hline T0 & 102.10 & 8.55 & 91.63 & 7.18 & 0.052 \\
\hline T1 & 97.83 & 20.10 & 87.23 & 6.03 & 0.068 \\
\hline T3 & 98.90 & 8.81 & 86.53 & 6.32 & 0.063 \\
\hline T5 & 94.37 & 6.69 & 84.67 & 4.77 & 0.073 \\
\hline T10 & 94.63 & 7.54 & 83.97 & 5.46 & 0.066 \\
\hline MAP T15 & 94.00 & 8.17 & 83.70 & 5.81 & \\
\hline
\end{tabular}

Abbreviation: MAP, mean arterial pressure.

between87.23 \pm 6.03 and $83.70 \pm 5.81$ in group R. No statistically significant differences in MAP were noted throughout the study between the groups ( - Table 6 and - Fig. 4 ).

\section{Discussion}

Cardiac surgery has undergone revolutionary changes over the last two decades with the invention of newer techniques, less invasiveness, and better outcomes. A faster recovery to normal function requires anesthetic techniques that avoid a long-lasting impact on physiological functions. A rational use of muscle relaxants also determines the outcome of cardiac surgery.

Fast-track anesthesia refers to extubation within 6 hours of the end of surgery, whereas ultrafast-track anesthesia refers extubation within 2 hours of the end of surgery. Of late, many studies have demonstrated the safety and efficacy of ultrafast-track anesthesia for off-pump CABG.

Hemodynamic stability is of prime importance in cardiac surgery owing to the low cardiac reserve in cardiac surgical patients. It is therefore necessary to avoid any agent including muscle relaxants that stimulates the cardiovascular system and thus increases the myocardial oxygen demand. ${ }^{8}$

Booij and Crul in 1983 spelled out the following requirements for the ideal neuromuscular blocking agent ${ }^{9}$ :

- Nondepolarizing mechanism of action.

- Rapid onset of action.

- Short duration of action.

- Rapid recovery.

- Noncumulative.

- No cardiovascular side effects.

- No histamine release.

- Reversible by cholinesterase inhibitors.

- Pharmacologically inactive metabolites.

- High potency.

Rocuronium has been shown to possess most of these properties of an "ideal" muscle relaxant except high potency..$^{10}$ This study was undertaken to study the intubating conditions and cardiovascular effects of rocuronium, the 


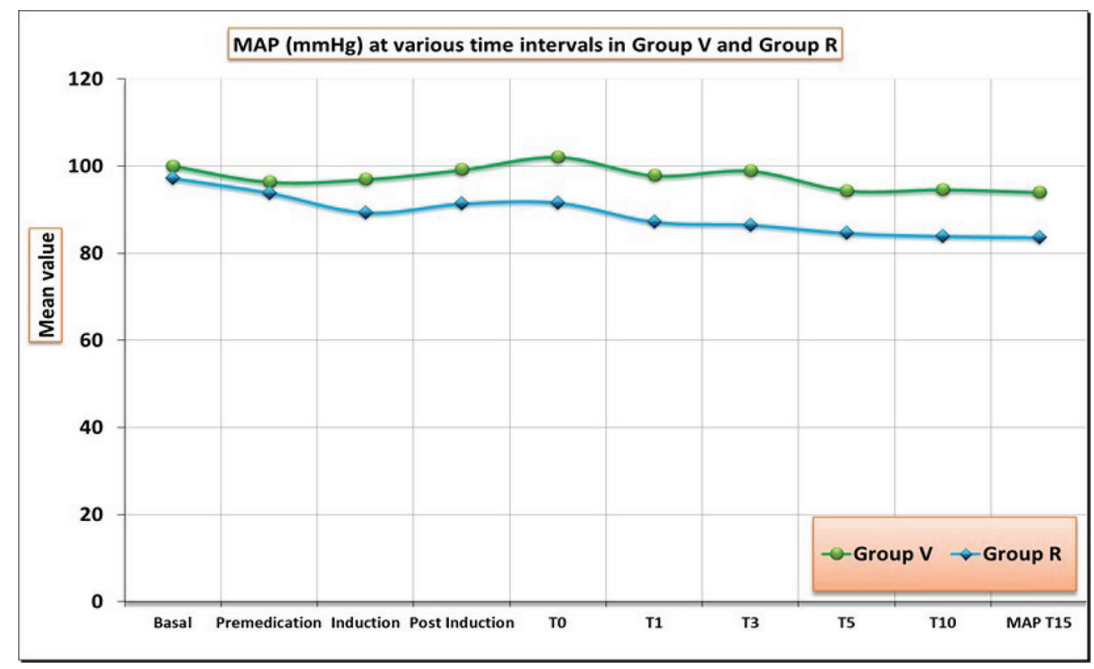

Fig. 4 MAP at various time intervals in group $V$ and group R. MAP, mean arterial pressure.

"near-ideal" muscle relaxant, and to compare it with vecuronium, an already established neuromuscular blocking agent in cardiac surgery.

Bartkowski et al demonstrated that rocuronium has an earlier onset of action with better intubating conditions as compared with vecuronium. ${ }^{11}$ van den Broek compared the onset of action and intubating conditions at 90 seconds following rocuronium, vecuronium, and mivacurium, and observed good-to-excellent intubating conditions at 90 seconds in a significantly larger number of patients after rocuronium than the other two compounds. ${ }^{12}$

Lin et al showed the intubation time in vecuronium to be 102.8 seconds and that in rocuronium to be 54.9 seconds. The intubation conditions were similar in both groups. ${ }^{13}$ Zhou et al showed that after rocuronium administration, 84\% had good-to-excellent intubating conditions at 60 seconds. ${ }^{14}$ Misra et al found that with rocuronium $(0.6 \mathrm{mg} / \mathrm{kg}), 90 \%$ of patients had acceptable intubating conditions at 60 seconds, whereas with vecuronium $(0.1 \mathrm{mg} / \mathrm{kg})$, only $13.3 \%$ patients had acceptable conditions at 60 seconds. ${ }^{15}$

There are only limited studies in the literature that have followed a design similar to that reported in this study, where intubating conditions were assessed at a predetermined time depending on the onset of action of the drug. The results of this study were consistent with those of the study by Gupta et al, who found that $0.6 \mathrm{mg} / \mathrm{kg}$ rocuronium and $0.1 \mathrm{mg} / \mathrm{kg}$ vecuronium provide good-to-excellent intubating conditions at 90 seconds and 180 seconds, respectively. ${ }^{16}$

An "ideal" neuromuscular blocking agent should produce cardiovascular stability, that is, it should not produce bradycardia, tachycardia, hypertension, or hypotension. The two intermediate-acting steroidal drugs, vecuronium and rocuronium, are considered to offer good cardiovascular stability. In this study, rocuronium in the dose of $0.6 \mathrm{mg} / \mathrm{kg}$ was compared with vecuronium in the dose of $0.1 \mathrm{mg} / \mathrm{kg}$ with respect to hemodynamic stability.

McCoy et al demonstrated that vecuronium lacks chronotropic effects, which may allow bradycardia to occur especially in patients receiving $\beta$-blockers or high-dose fentanyl anesthesia. In this study, we noted a mild fall in HR of approximately 5 beats (basal 85.9 to postinduction 81.23 ) after vecuronium. However, this fall was not associated with any hemodynamic instability. ${ }^{17}$

The findings of this study are in agreement with the study of Maddineni et al, who studied the hemodynamic effects of rocuronium in the doses of $0.6 \mathrm{mg} / \mathrm{kg}$ and $0.9 \mathrm{mg} / \mathrm{kg}$ under balanced and volatile anesthesia and concluded that no significant change in HR occurred with both doses and both techniques. ${ }^{18}$ Kale et al and Nitschmann et al also found rocuronium to be devoid of any significant cardiovascular changes causing hemodynamic instability when compared with vecuronium. ${ }^{19,20}$ Similar findings have been reported by Hudson et al and Levy et al..$^{21,22}$

This finding of this study that vecuronium did not cause any significant change in BP is in accordance with van den Broek et al, who studied the hemodynamic effects of vecuronium and found that it does not influence SBP and DBP. ${ }^{12}$ It also correlates with the study of Robertson et al and Kaufman et al, who found no significant changes in arterial pressure secondary to even large doses of vecuronium (up to $0.4 \mathrm{mg} / \mathrm{kg})^{23,24}$

The hemodynamic findings in the rocuronium group correlate with the study of Levy et al, who found no difference in $\mathrm{BP}$ when evaluating the hemodynamic parameters and histamine release of rocuronium in doses up to $1.2 \mathrm{mg} / \mathrm{kg}^{22}$

A rise in SBP was observed during laryngoscopy and intubation in the vecuronium group. When compared with rocuronium, although the difference was significant, these effects were transient and not associated with any hemodynamic instability. This finding is in correlation with the studies of McCoy et al, Kale et al, Carroll et al, and Virmani et al, who have all found no difference in any of the hemodynamic variables between the two groups during comparison. ${ }^{17,19,25,26}$

In contrast to our study, Robertson et al found statistically significant increases from baseline in one or more (HR, BP) hemodynamic parameters in the rocuronium group when 
compared with vecuronium. These changes were attributed to the vagolytic action of rocuronium bromide..$^{23}$

Studies by Maddineni et al, and Naguib et al have reported no significant change in MAP after rocuronium administration. The findings of this study are in harmony with these results. ${ }^{18,27}$

No adverse effects such as bronchospasm, hypotension, or rashes were noted in any patient during the study.

\section{Conclusion}

This study shows that rocuronium provides good-to-excellentintubating conditions and is devoid of any significant cardiovascular changes causing hemodynamic instability when compared with vecuronium in patients undergoing elective ultrafast-track off-pump CABG. In conclusion, although vecuronium is a gold standard in cardiac surgery as a neuromuscular blocking agent, rocuronium bromide can be advocated as the drug of choice in elective as well as emergency cardiac surgery where rapid intubation will be beneficial without compromise of hemodynamic stability.

\section{Funding}

None.

\section{Conflicting of Interest}

None.

\section{Acknowledgment}

The authors would like to acknowledge Dr Pallavi Bhange for her help in collecting the research data.

\section{References}

1 Kanchi M, Nair HC, Banakal S, Murthy K, Murugesan C. Haemodynamic response to endotracheal intubation in coronary artery disease: direct versus video laryngoscopy. Indian J Anaesth 2011;55(3):260-265

2 Murphy GS, Szokol JW, Vender JS, Marymont JH, Avram MJ. The use of neuromuscular blocking drugs in adult cardiac surgery: results of a national postal survey. Anesth Analg 2002;95(6):1534-1539

3 Morris RB, Cahalan MK, Miller RD, Wilkinson PL, Quasha $\mathrm{AL}$, Robinson SL. The cardiovascular effects of vecuronium (ORG NC45) and pancuronium in patients undergoing coronary artery bypass grafting. Anesthesiology 1983;58(5): 438-440

4 Rørvik K, Husby P, Gramstad L, Vamnes JS, Bitsch-Larsen L, Koller ME. Comparison of large dose of vecuronium with pancuronium for prolonged neuromuscular blockade. $\mathrm{Br} \mathrm{J}$ Anaesth 1988;61(2):180-185

5 Wierda JMKH, de Wit APM, Kuizenga K, Agoston S. Clinical observations on the neuromuscular blocking action of Org 9426, a new steroidal non-depolarizing agent. $\mathrm{Br} J$ Anaesth 1990;64(4):521-523

6 Naguib M, Cynthia AL, Pharmacology of muscle relaxants and their antagonists. In: Miller RD, ed. Miller's Anesthesia. 6th ed. Philadelphia, PA: Elsevier Churchill Livingstone; 2005 494-495

7 Goldberg ME, Larijani GE, Azad SS, et al. Comparison of tracheal intubating conditions and neuromuscular blocking profiles after intubating doses of mivacurium chloride or succinylcholine in surgical outpatients. Anesth Analg 1989;69(1):93-99
8 Kuhn C, Werdan K, Hemodynamic monitoring. In: Holzheimer RG, Mannick JA, eds. Surgical Treatment: Evidence-Based and Problem-Oriented. Munich: Zuckschwerdt; 2001

9 Booij LHDJ, Crul JF, A comparison of vecuronium with the hypothetical ideal neuromuscular blocking drug. In: Agoston S, Bowman WC, Miller RD, Viby-Mogensen J, eds. Clinical Experiences with Norcuron. Amsterdam: Excerpta Medica; 1983 3-8

10 Kopman AF. Pancuronium, gallamine, and d-tubocurarine compared: is speed of onset inversely related to drug potency? Anesthesiology 1989;70(6):915-920

11 Bartkowski RR, Witkowski TA, Azad S, Lessin J, Marr A. Rocuronium onset of action: a comparison with atracurium and vecuronium. Anesth Analg 1993;77(3):574-578

12 van den Broek L, Hommes FD, Nap HJ, Wierda JM. Rocuroniumand mivacurium-induced neuromuscular block and intubating conditions: a comparison with vecuronium. Eur J Anaesthesiol Suppl 1995;11:27-30

13 Lin PL, Liu CC, Fan SZ, Chao A, Shin SC, Tai YT. Comparison of neuromuscular action of rocuronium, a new steroidal non-depolarizing agent, with vecuronium. Acta Anaesthesiol Sin 1997;35(3):127-131

14 Zhou TJ, White PF, Chiu JW, et al. Onset/offset characteristics and intubating conditions of rapacuronium: a comparison with rocuronium. Br J Anaesth 2000;85(2):246-250

15 Misra MN, Agarwal M, Pandey RP, Gupta AA. Comparative study of rocuronium, vecuronium and succinylcholine for rapid sequence induction of anaesthesia. Indian J Anaesth 2005;49:469-473

16 Gupta N, Sharma M, Gupta P, Agarwal D. Comparative evaluation of onset time intubating condition judged by clinical criteria and hemodynamic response after the intubating dose of rocuronium and vecuronium. Int J Appl Basic Med Res 2015;5(3):39-44

17 McCoy EP, Maddineni VR, Elliott P, Mirakhur RK, Carson IW, Cooper RA. Haemodynamic effects of rocuronium during fentanyl anaesthesia: comparison with vecuronium. Can J Anaesth 1993;40(8):703-708

18 Maddineni VR, McCoy EP, Mirakur RK, McBride RJ. Onset and duration of action and hemodynamic effects of rocuronium bromide under balanced and volatile anesthesia. Acta Anaesthesiol Belg 1994;45(2):41-47

19 KaleS, KaneD, DewoolkarL, PandyaS. Comparison of haemodynamic stability with intubating dose of IV rocuronium bromide vs intubating dose of IV vecuronium bromide in cardiac surgery patients. Internet J Anesthesiol 2007;12(1):1-6

20 Nitschmann P, Oberkogler W, Hertsig M, Schwarz S. Comparison of haemodynamic effects of rocuronium bromide with those of vecuronium in patients undergoing CABG surgery. Eur J Anaesthesiol Suppl 1994;9(Suppl.) :113-115

21 Hudson ME, Rothfield KP, Tullock WC, Firestone LL. Haemodynamic effects of rocuronium bromide in adult cardiac surgical patients. Can J Anaesth 1998;45(2):139-143

22 Levy JH, Davis GK, Duggan J, Szlam F. Determination of the hemodynamics and histamine release of rocuronium (Org 9426) when administered in increased doses under $\mathrm{N} 2 \mathrm{O} /$ O2-sufentanil anesthesia. Anesth Analg 1994;78(2):318-321

23 Robertson EN, Hull JM, Verbeek AM, Booij LH. A comparison of rocuronium and vecuronium: the pharmacodynamic, cardiovascular and intra-ocular effects. Eur J Anaesthesiol Suppl 1994;9(Suppl):116-121

24 Kaufman JA, Dubois MY, Chen JC, Lea DE. Pharmacodynamic effects of vecuronium: a dose response study. J Clin Anesth 1989;1(6):434-439

25 Carroll MT, Mirakhur RK, Lowry DW, McCourt KC, Kerr C. Neuromuscular blocking effects and train-of-four fade with cisatracurium: comparison with other nondepolarising relaxants. Anaesthesia 1998;53(12):1169-1173 
76 Shah, Kulshrestha

26 Virmani S, Tempe DK, Datt V, et al. Effect of muscle relaxants on heart rate, arterial pressure, intubation conditions and onset of neuromuscular block in patients undergoing valve surgery. Ann Card Anaesth 2006;9(1):37-43
27 Naguib M, Samarkandi AH, Bakhamees HS, Magboul MA, el-Bakry AK. Histamine-release haemodynamic changes produced by rocuronium, vecuronium, mivacurium, atracurium and tubocurarine. Br J Anaesth 1995;75(5):588-592 